\title{
SEDIMENTARY CHARACTERISTICS OF SAMPLES COLLECTED FROM SOME SUBMARINE CANYONS
}

\author{
A. H. BOUMA \\ Geological Institute, State University, Utrecht (The Netherlands)
}

(Received October 20, 1964)

\section{SUMMARY}

Oriented rectangular cores of $20.3 \times 30.5 \mathrm{~cm}$ and $45.7 \mathrm{~cm}$ high have been collected in a number of submarine canyons off southern California (U.S.A.) and off the southern tip of Baja California (Mexico) for a detailed study of their sedimentary structures.

By applying several methods, mainly X-ray radiography, to vertical slices of the sediment samples, an abundance of information was obtained.

The clayey shelf sediments in southern California reveal few primary sedimentary structures, which are only slumped and reworked by burrowing organisms. Sediments from the axis of the submarine canyons are mainly coarse and contain parallel lamination, current-ripple lamination, and sometimes small-scale graded bedding; slump phenomena and locally some reworking by animals are less important structures. A short distance outside the canyon axis the samples are much finer in grain size; they show fewer primary structures and more secondary ones. Sometimes the whole sample is completely disturbed by burrowing organisms, as is the case in a sample collected from a canyon terrace.

One sample was collected from a gully on the apron of the La Jolla Fan Valley. This is similar to the facies model of ancient turbidites with regard to the type and succession of the sedimentary structures present. A box core from a small basin in the middle of the Gulf of California was found to be entirely reworked by organisms.

\section{INTRODUCTION}

Three short cruises (LC-IV, -V and -VI) were made with the Research Vessel "Spencer F. Baird" in the area off San Diego (California, U.S.A.) during November and December 1962. Special attention was given to the topography and sediments of the La Jolla and the Coronado Canyon. In January 1963, the submarine canyons around 
the southern tip of Baja California (Mexico) were examined, using the same vessel (cruise SJ). ${ }^{1}$

Since the cross section of normal piston and gravity cores is somewhat small for the study of sedimentary structures, there was the possibility of building a box sampler as developed by REINECK $(1958,1963 a)$. Some alterations were made for deep-water work (Bouma and SHePard, 1964; Bouma and Marshall, 1964). Vertical "undisturbed" samples can be collected by means of this device, containing a sample box which is $20.3 \times 30.5 \mathrm{~cm}$ in ground plan and $45.7 \mathrm{~cm}$ high. Samples have been obtained at places where piston and gravity cores failed. Practically all of the attempts were successful and the box cores ranged between 15 and $45 \mathrm{~cm}$ in height, with an average of over $40 \mathrm{~cm}$ (Bouma and MArshall, 1964, table I). A self-locking compass was added to the sampler for obtaining the orientation of possible "current marking structures" of the samples (BOUMA, 1964a).

One of the vertical sides of each box could be removed, and a vertical slice sediment of about $5 \mathrm{~cm}$ thick was sliced off (for details see BoUMA and MARSHALL, 1964). Such a slice was thinned down to $9-18 \mathrm{~mm}$, and then an X-ray radiograph was made (Hamblin, 1962; Calvert and Veevers, 1962; Bouma, 1963) (for details see BoumA, 1964e). In order to obtain a maximum of detail the Kodak Industrial AA type of film was employed. The contrast between several parts of the exposed film can be so high that it may be almost impossible to make decent prints of them. After drying out carefully in the refrigerator for some days the sediment slices showed some details, and black and white photographs were made.

It will be superfluous to describe all the aspects of the investigated submarine canyons in detail; the reader may be referred to the excellent contributions and to the references given in them (SHEPARD and EMERY, 1941; BUfFINGTON, 1951, 1964; SHEPARD, 1951, 1961, 1963a, b, 1964; EMERY, 1960; SHEPARD and EINSELE, 1962; EMERY and HülSEMANN, 1963; Dill, 1964a, b). Our contribution will be restricted to the observations made on the sedimentary structures and to those grain-size analyses that are of direct importance to these structures.

The canyons incised into the continental shelf off San Diego (Fig.1) are mainly cut in Eocene shales, sandstones and conglomerates. The incisions around the southern tip of Baja California (Fig.2) expose sides in Miocene and Pliocene formations, as well as in crystalline rocks (Vigia Canyon: granite and laminated shales; San Lucas Canyon: granite; Santa Maria Canyon: granite, gneiss, sediments; Salado Canyon: crystalline rock; Arena Canyon: crystalline rock?; Pescadero Canyon: granite. See SHEPARD, 1964).

1 These sea trips were carried out under the direction of F. P. Shepard. His work was largely supported by the Office of Naval Research under Contract No. 2216 (01). During this period the present author was studying at the Scripps Institution of Oceanography with a post-doctoral fellowship provided by the Ford Foundation. 


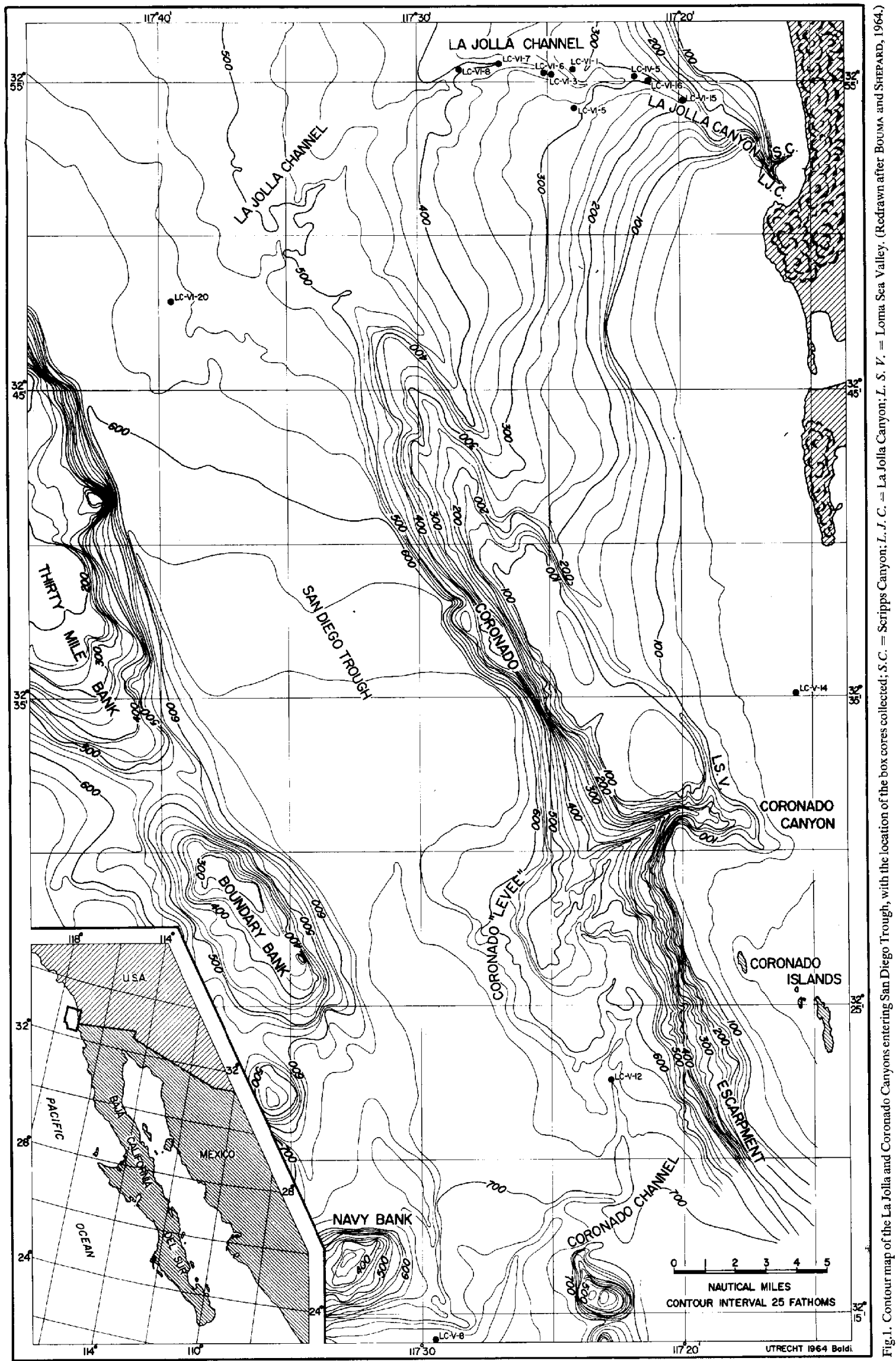




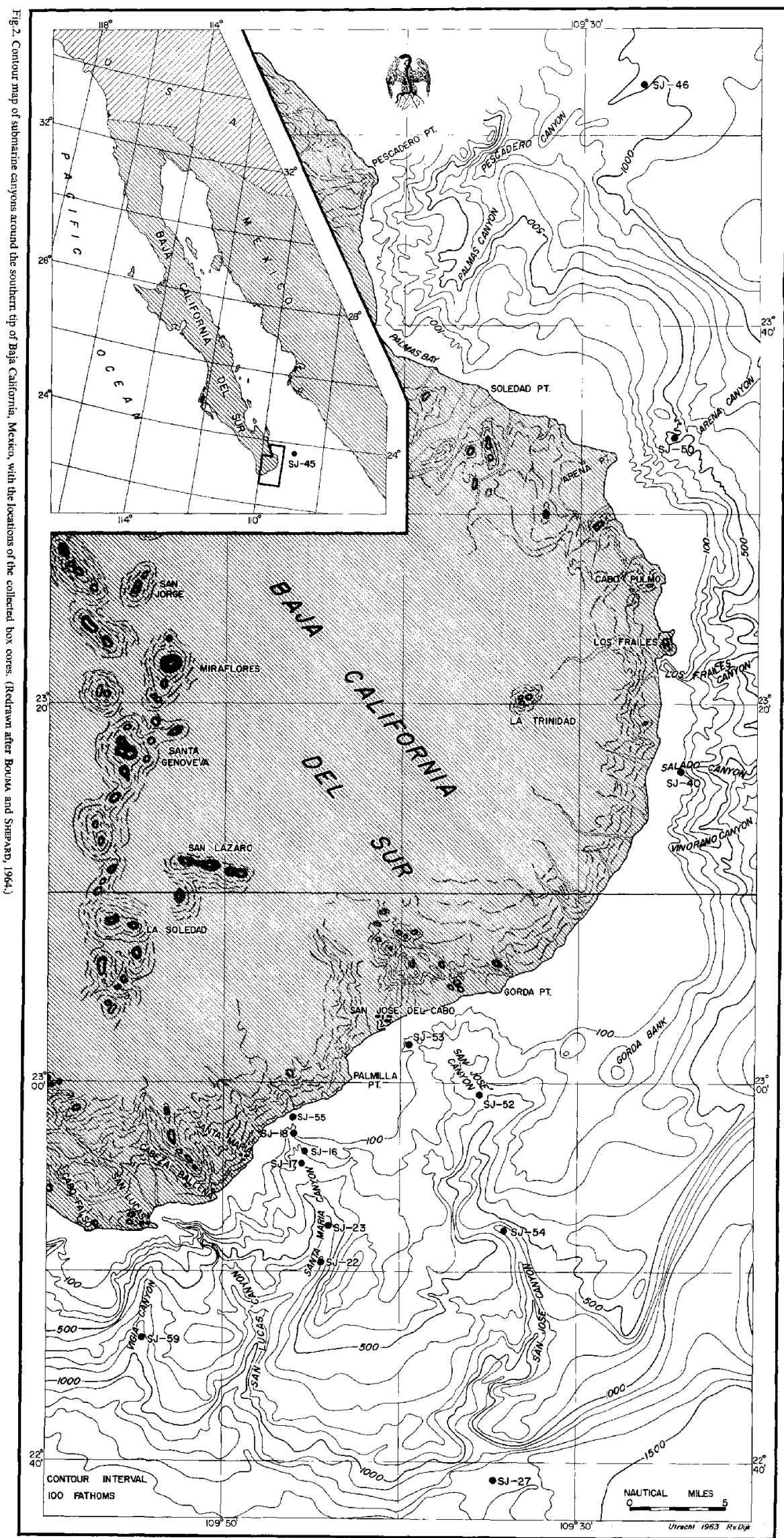




\section{DESCRIPTION OF THE SAMPLES COLLECTED}

All rectangular cores collected during the four mentioned cruises will be described in groups with their respective environmental position. In spite of the low number of samples and the small portion of all submarine canyons that could be investigated, some general lines in the divisions seem to be justified. Too few box samples have been obtained within a canyon for us to be able to give possible changes in the filling from the head to the fan (Fig.1, 2).

To avoid unnecessary duplication of figures the reader will be referred to most of the photographs given by Bouma (1964e). Also, no extensive interpretation of sedimentary properties, visible in the prints of the radiographs, will be given since we have tried to do this in the mentioned paper.

\section{Canyon axis}

Samples collected in the axis of a canyon are characterized by a high amount of sandy and/or gravelly material when compared to samples outside the axis. Part of the variations in the series of box cores obtained from the axes are different between the canyons, due to various types of sources; presumably they also differ slightly with regard to their position to the actual axis. This variation lies beyond our possibility of observation. Compared to the samples received from the sides outside the actual part one gets the impression that the real axial part is normally very small, in the order of $10-50 \mathrm{~m}$.

A total of twelve samples were recovered from what is called the canyon axis. These came from the La Jolla Fan Valley: LC IV-5 at 310 fathoms (Fig.3, 4), LC VI-3 at 362 fathoms (BoumA, 1964e, fig.16, 17), LC VI-6 at 368 fathoms, LC VI-7 at 400 fathoms (Fig.5, 6), LC VI-8 at 416 fathoms; in the Santa Maria Canyon SJ-55 at 35 fathoms (Fig.7), SJ-17 at 368 fathoms (Fig.8 and BoumA, 1964e, fig.4, 5), SJ-23 at 655 fathoms; in the San José Canyon SJ-53 at 132 fathoms and SJ-52 at 390 fathoms (Fig.9); in the Arena Canyon SJ-50 at 565 fathoms; and in the Vigia Canyon SJ-59 at 962 fathoms (for positions see Fig.1, 2).

All these samples, except SJ-55 off the head of San Jose Canyon, are thin to medium bedded. Within a bed other sedimentary structures can often be detected. The sandy parts are only occasionally reworked by burrowing organisms and even the occurrence of slumping is not common. If clayey-sand beds are present some burrows can be observed in the radiograph.

Sample LC IV-5 from a depth of 310 fathoms collected in the La Jolla Fan Valley presents five beds of clayey-sand and sand alternating with different thicknesses (Fig.3). The thick sand bed contains irregular lamination and a large downbowing structure (point 1 ); the lower sand bed vaguely contains some inclined lamination (point 2). Comparing the photograph with the radiograph (Fig.4) one observes the bending of the laminae at the sides of the down-bowing property. Concerning this character, the radiograph gives the idea of a large vertical burrow. This 


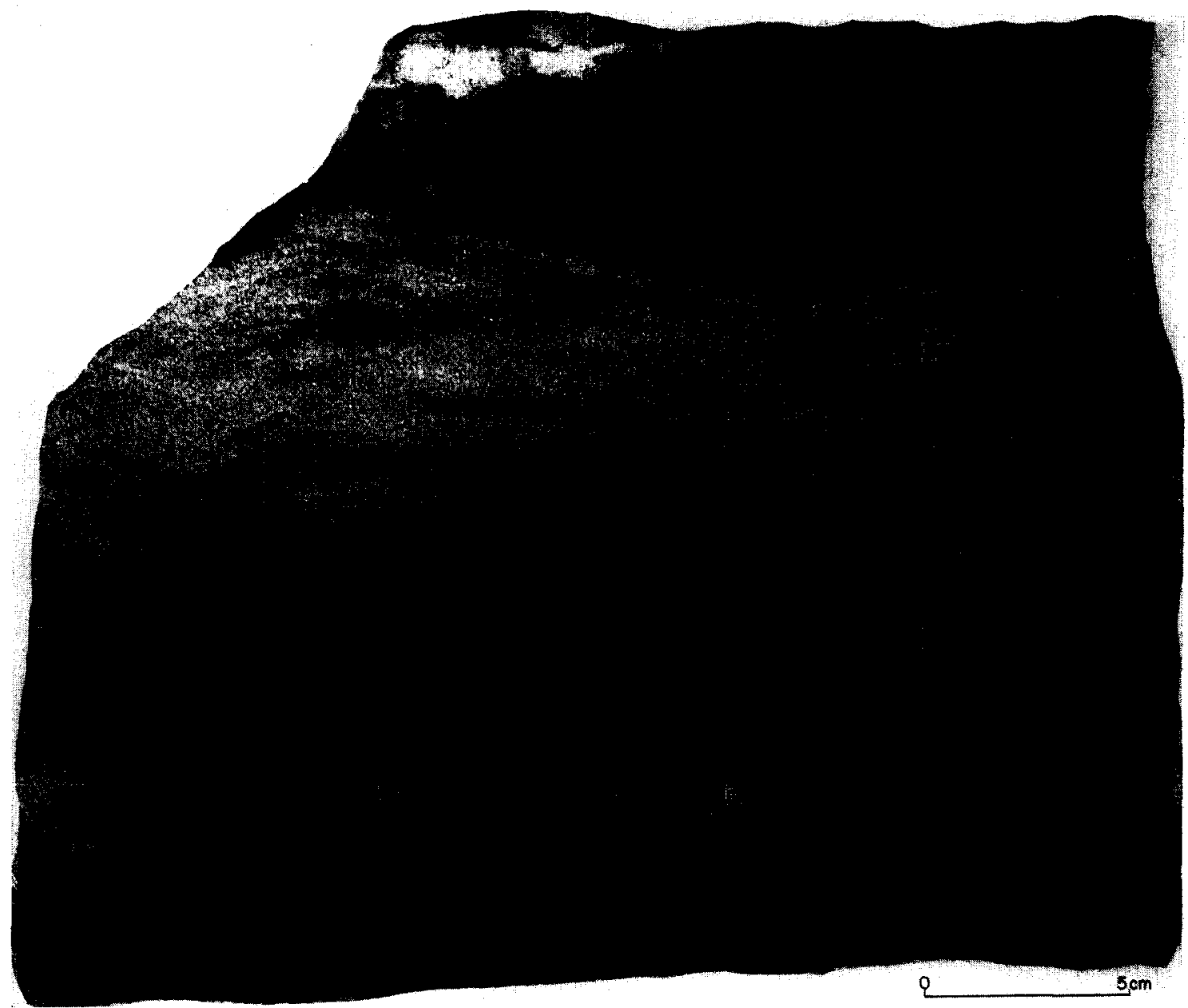

Fig.3. Photograph of a vertical slice of sample LC VI-5, collected in the axial part of the La Jolla Channel at a depth of 310 fathoms. The down-bowing structure $(I)$ is a large-sized vertical burrow.

was confirmed by analysing a second slice from this sample, cut at $30 \mathrm{~mm}$ from the first one.

The radiograph at point 2 clearly reveals the ripple lamination. Fig. 4 shows the irregularity of the parallel lamination with a number of wedging-outs on the side toward which the ripple dips. This implies that this irregular laminated part is a combination of parallel lamination and poorly developed current ripple lamination.

The clayey-sand beds are built up by many thin sand laminae in a more clayey mass. The lamination is irregular, due to minor sliding under the influence of the somewhat older large burrow.

No other data could be obtained from this slice, except the presence of a plant fragment (point 3) in Fig.4. The black dots (point 4) and the crack (point 5) are artificial. 


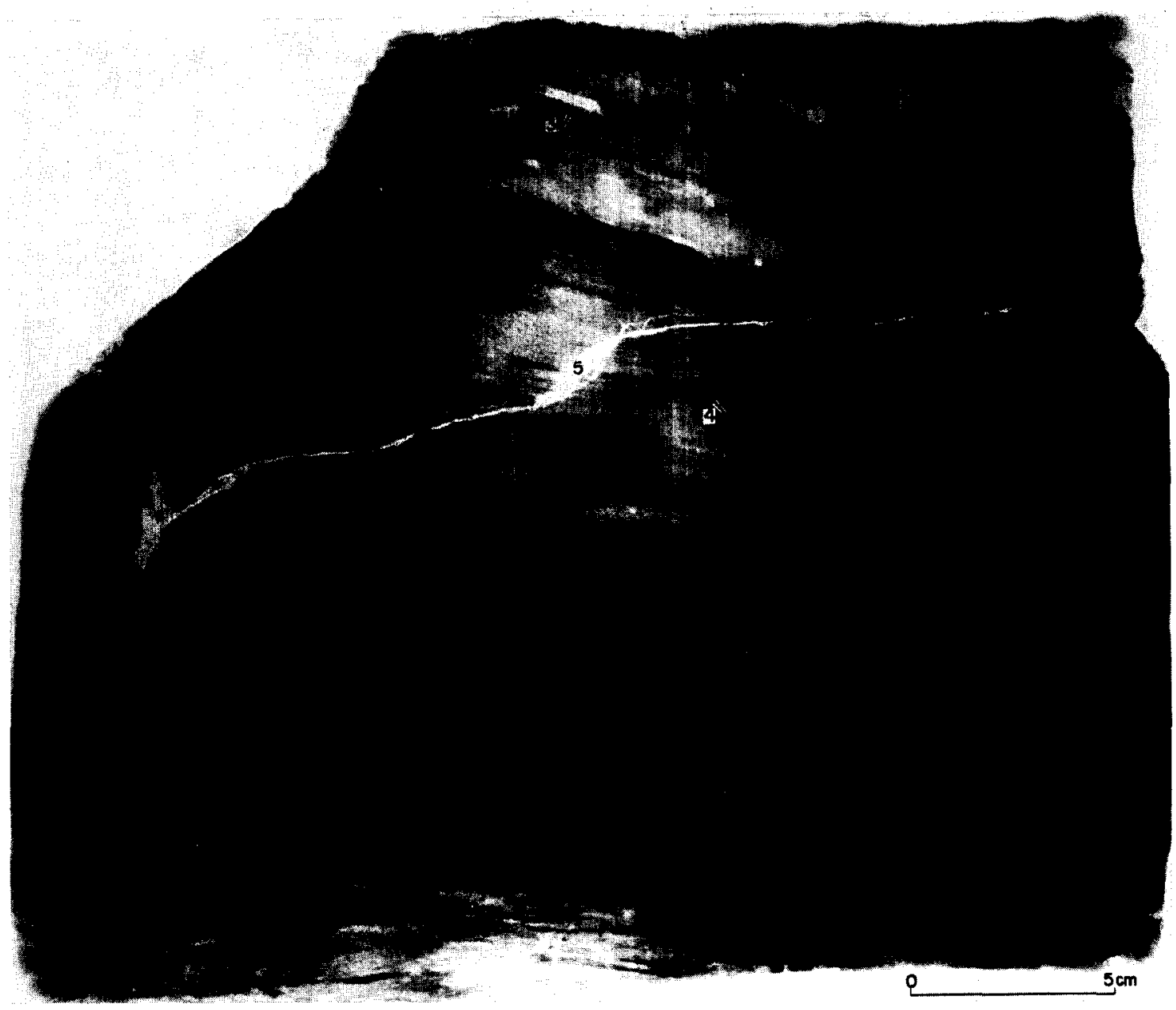

Fig.4. Print of a radiograph made of the slice given in Fig.3. The black dots (4) and the white crack (5) are artificial. Note the wedging-out of laminae and the fore-set bedding (2). Slice thickness: $10 \mathrm{~mm}$; Kodak Industrial film AA, $40 \mathrm{kV}, 5 \mathrm{~mA}, 1 \mathrm{~min}$.

Sample LC VI-3 collected at a depth of 362 fathoms is presented in fig. 16 and 17 of Bouma (1964e) and its characters are described. The sample is built up by alternating beds of sand, clayey-sand and sandy-clay. The thickest sand bed contains parallel lamination in its lower part and ripple lamination in its upper part. The upper bedding plane is rippled. The fore-sets dip to $240^{\circ}$. The rippled part can be split up into five horizons, of which the upper one contains complete current ripples. The transition from the parallel lamination to the ripple lamination is erosional and not gradual.

The other sandy beds vary in thickness between 30 and $7 \mathrm{~mm}$. When they are somewhat silty they contain a high amount of crushed plant fragments and mica. These layers show a folded lamination which is somewhat comparable to convolute 


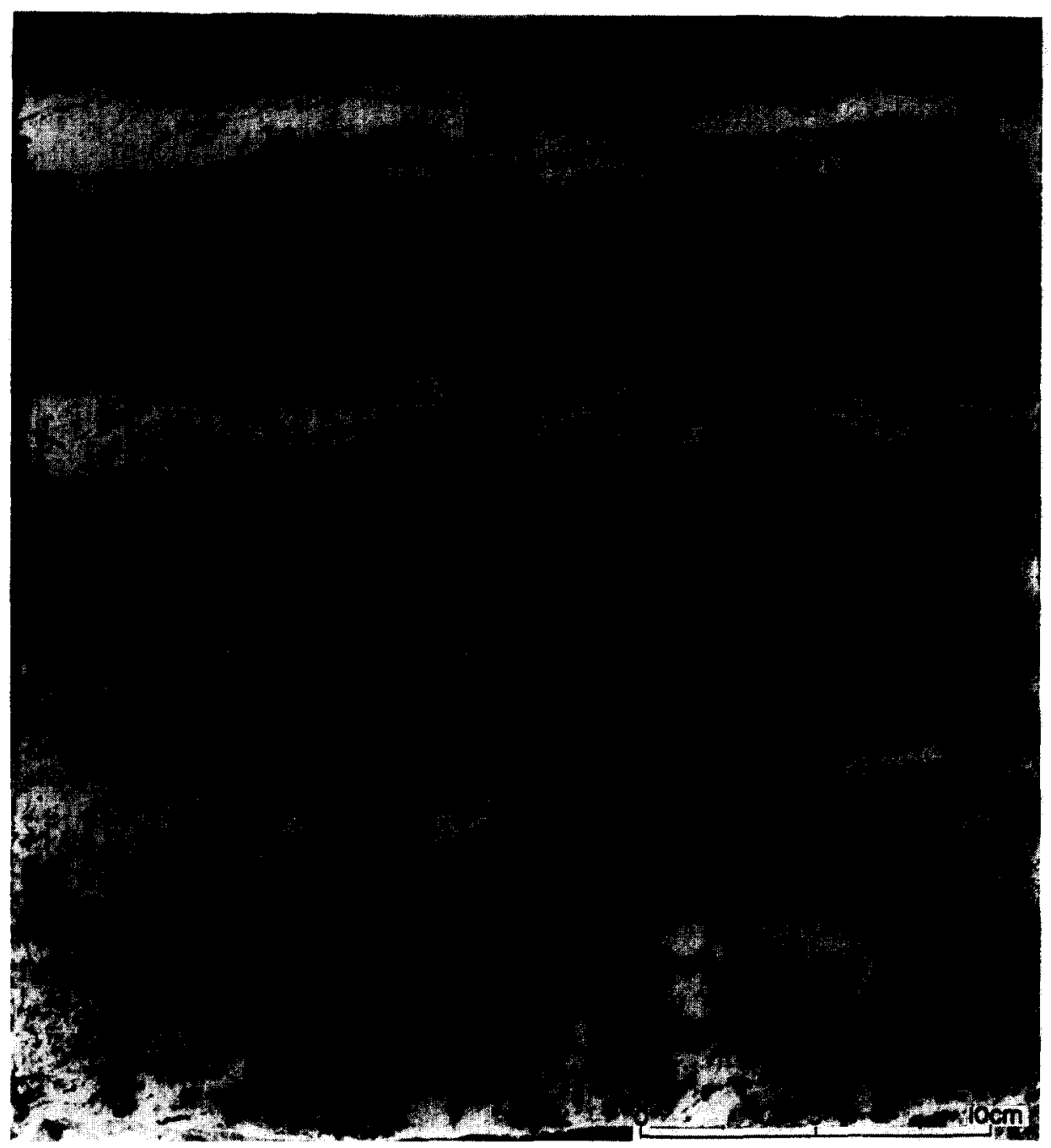

Fig.5. Photograph of a vertical slice of sample LC VI-7, collected in the axis of the La Jolla Channcl at a depth of 400 fathoms. This sample is comparable with the organic mat known from canyon heads. It consists of alternating layers of sand and clayey sand with an abundance of plant fragments.

lamination. The clayey parts contain vertical burrowing. Examining these parts a decrease of silt content upward can be observed.

Samples LC VI-6 and LC VI-8 at depths of 368 and 416 fathoms, respectively, are completely sandy with grain sizes ranging from fine to medium sand. The content of mica flakes is rather high. Radiographs do not reveal much more than can be seen from lacquer peels made from the slices. Both samples contain some lamination to thin bedding (similar to sample SJ-52: Fig.9), vaguely inclined bedding dipping in downcurrent direction, shell fragments and clay pebbles, erosional lines and slumping. The slices reveal a slight tendency to graded bedding in their lower parts. 


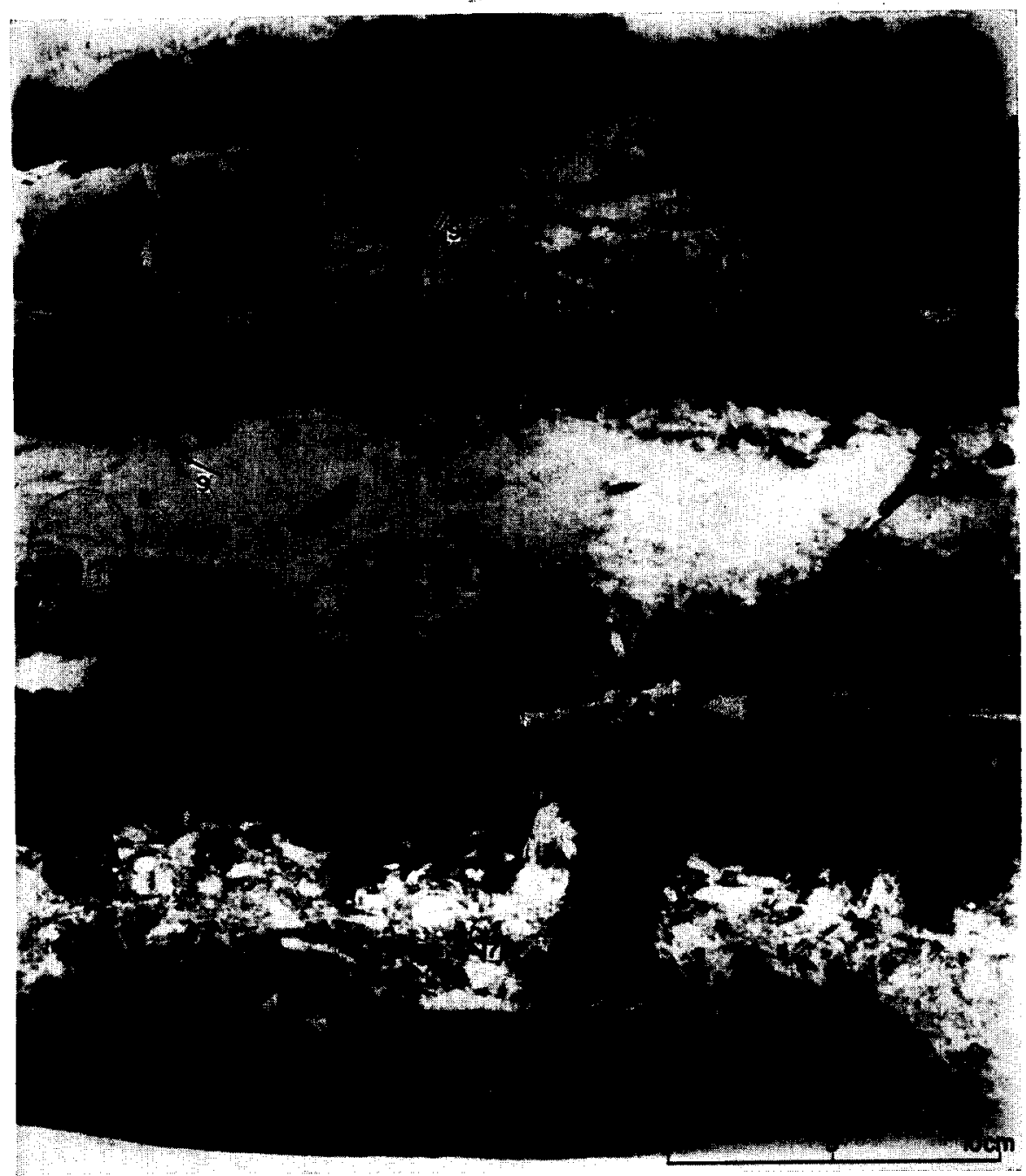

Fig.6. Print of a radiograph made of the slice given in Fig.5. The black parts are sandy, grey parts clayey sandy and the white spots (7) are images of plant fragments. Slice thickness: 20 mm; Kodak Industrial film AA, $40 \mathrm{kV}, 5 \mathrm{~mA}, 150 \mathrm{sec}$.

Sample LC VI-7 (depth 400 fathoms) is a type of sediment which is often found in an uncompacted state in the heads of the canyon during SCUBA dives (see also Dill, 1964b). The sample consists of an alternation of more and less clayey sand (point 6) with a high content of organic material (organic mat). In the normal pictures (Fig.5) the contacts are irregular and no other structures can be noticed. The radiograph (Fig.6) reveals that the distribution of organic remains from kelp and sea grass (light coloured spots: point 7) is very irregular. Some layering can be seen; in the upper sand layer some parallel lamination and fore-set bedding, dipping downcurrent, is visible. The irregular dark coloured patches of sand (point 8 ) may be due 


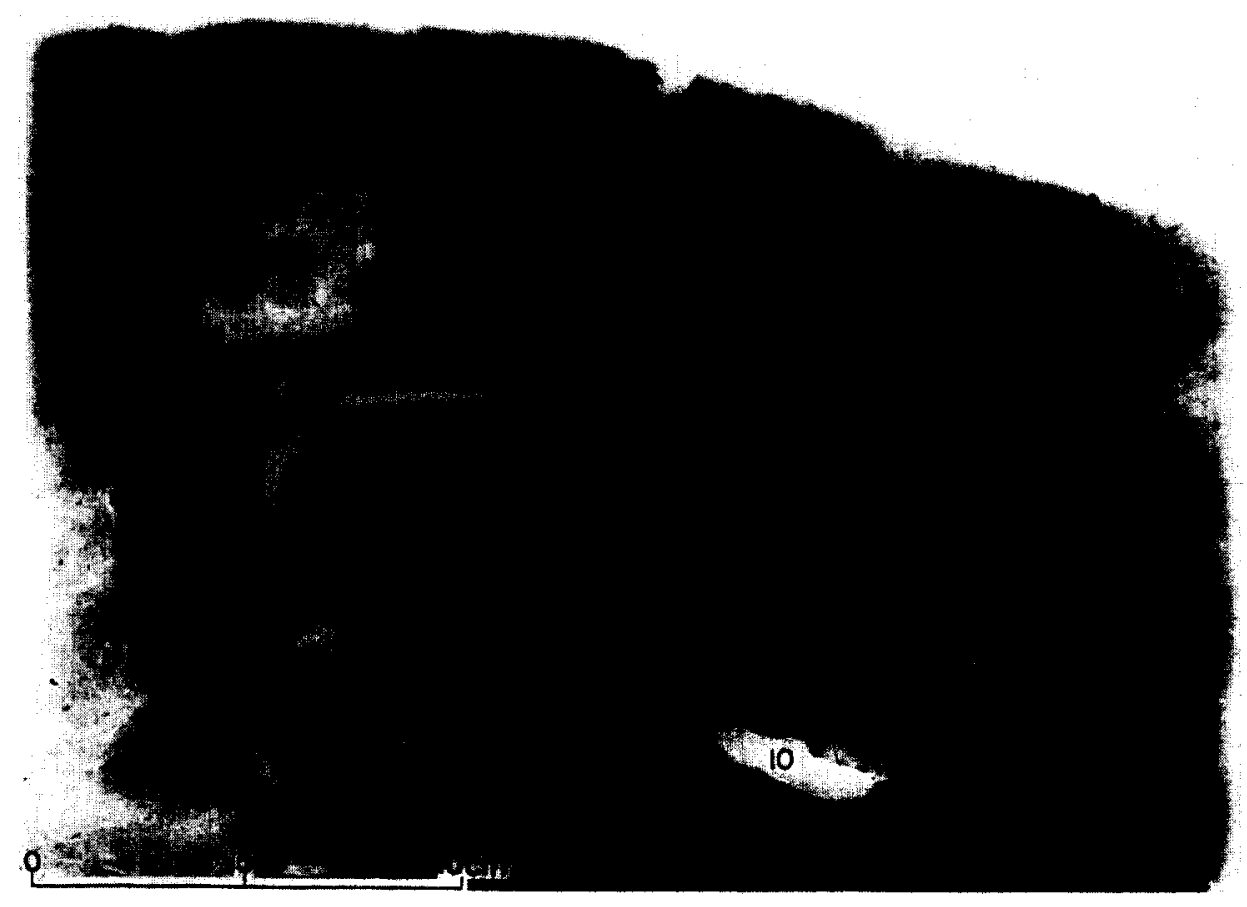

Fig.7. Print of the upper part of the radiograph made of a vertical slice of sample SJ-55, collected in the axis of the head of Santa Maria Canyon at a depth of 35 fathoms. The only contents of the slightly clayey sand deposit are wood rests $(I 0)$ and shell fragments (II). Slice thickness: $12 \mathrm{~mm}$; Kodak Industrial film AA, $40 \mathrm{kV}, 5 \mathrm{~mA}, 4 \mathrm{~min}$.

to the filling of hollows between the organic material. The clayey parts (light gray) are somewhat mottled. Part of the irregularities can be interpreted as burrows (point 9).

Sample SJ-55, collected in the head of the Santa Maria Canyon at a depth of 35 fathoms is the only sample in this series which does not show any bedding. Fig.7 presents only the upper part of this sample due to its uniformity. The whole sediment is a very slightly clayey sand with an abundance of wood fragments (point 10 ) and shell fragments (point $I I$ ).

In Fig.8 the print of a radiograph of sample SJ-17 (368 fathoms) is given. In the photograph (Bouma, 1964e, fig.4) one only observes a gravelly, coarse sandy, basal part. The fragments from unweathered granite range from 1 to $27 \mathrm{~mm}$ in size. The radiograph does not reveal bedding or any other sedimentary structure in this part.

The overlying material consists of a clayey sand. Grain size analyses indicate slight variations in size distribution but no decrease of size upward (Fig.10).

The rectangular diagram is used here to present the size-frequency distribution, since relative relationships between samples within one core can be analysed more easily than can be obtained from cumulative curves (see DoEGLas, 1955, 1960, 1962). A 


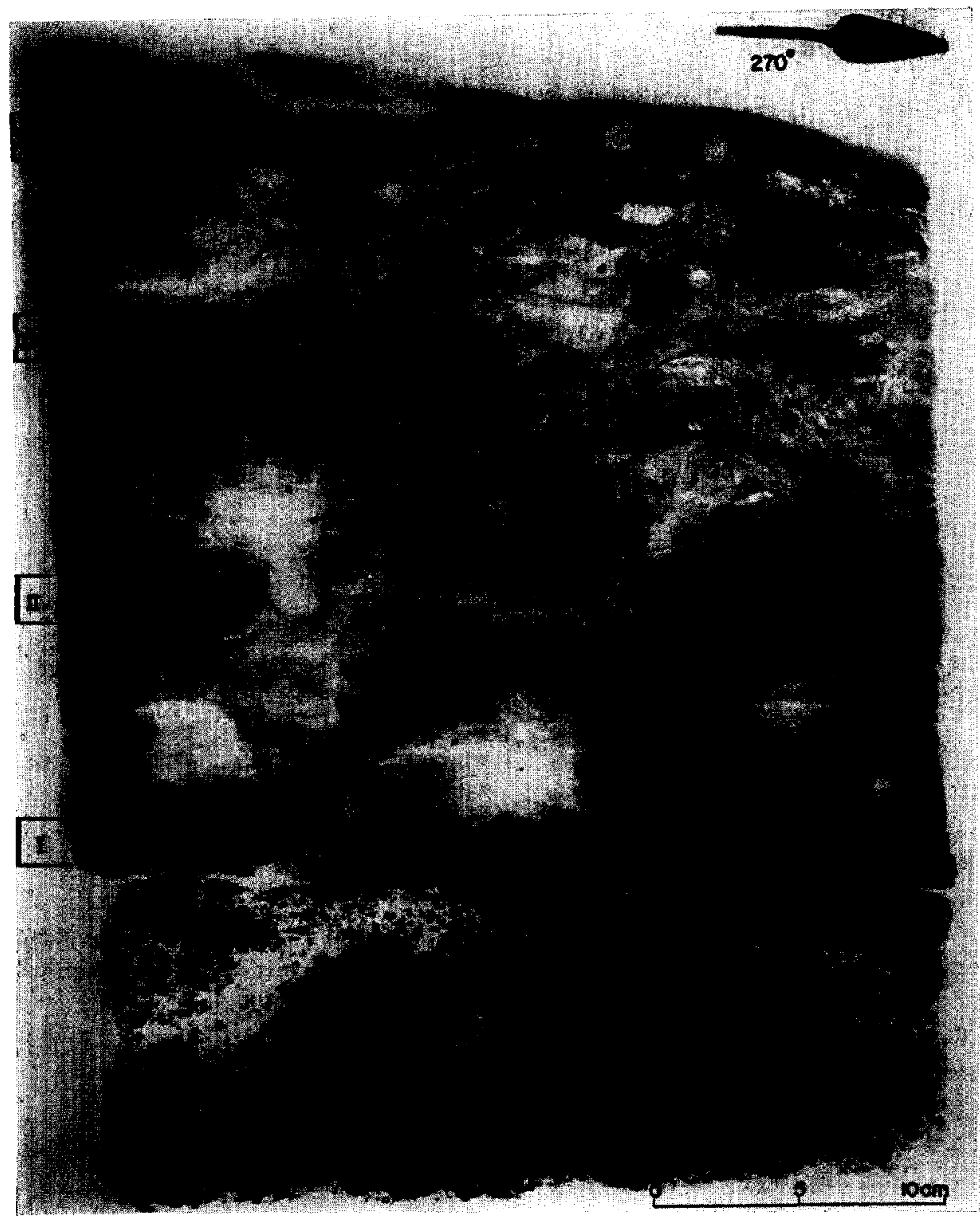

Fig.8. Print of a radiograph made of a vertical slice of sample SJ-17, collected in the axis of the Santa Maria Canyon at a depth of 368 fathoms. The lower part consists of unweathered granitic material. The upper part is a clayey sand in which the sedimentary structures are partly masked by slump action. The numbers at the side indicate sampling intervals for size analyses (see Fig.10). Slice thickness: 12-18 mm; Kodak Industrial film AA, $40 \mathrm{kV}, 5 \mathrm{~mA}, 3 \mathrm{~min}$ (see also BoumA, 1964e, fig. 4, 5). 


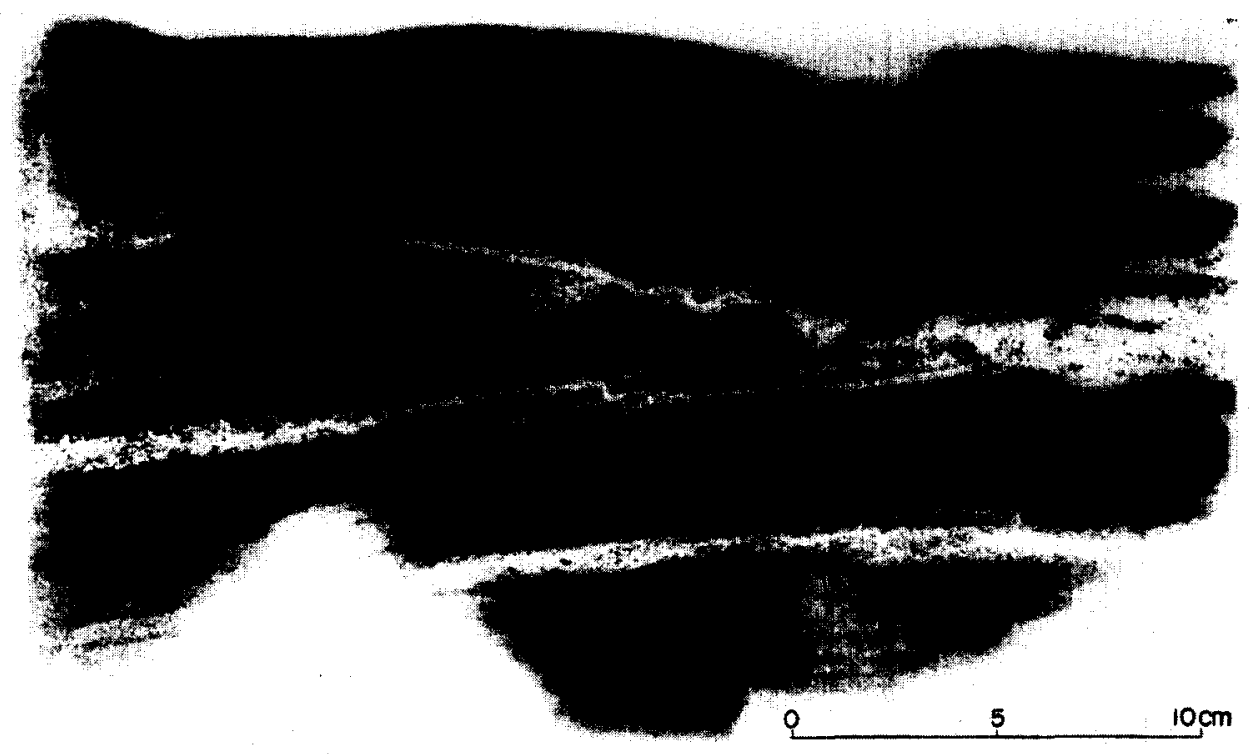

Fig.9. Print of a radiograph made of a vertical slice of sample S.-52, collected in the axis of the San José Canyon at a depth of 390 fathoms. The sandy material is thin-bedded and laminated and contains clay pebbles (/2). Slice thickness: $20 \mathrm{~mm}$; Kodak Industrial film AA, $40 \mathrm{kV}, 5 \mathrm{~mA}, 210 \mathrm{sec}$.

number of properties can be observed of which irregular lamination and burrows are predominant (see BoumA, 1964e, fig.5). All have been disturbed by slumping.

Sample SJ-23 (depth 655 fathoms) consists of four layers, each about 6-7 cm thick. All are of gravelly sand and show an indistinct graded bedding. Apart from these two structures no other properties could be observed.

Both samples from the San José Canyon contain only thin bedding to coarse parallel lamination; SJ-53 from a depth of 132 fathoms consists of coarse gravel and sand (up to $6 \mathrm{~cm}$ diameter), and SJ-52 comes from 390 fathoms depth. The radiograph of the latter sample shows a number of oval spots (point 12, Fig.9). These are the images of clay pebbles in the rather homogeneous sand.

Sample SJ-50, collected at a depth of 565 fathoms in the Arena Canyon, is about $26 \mathrm{~cm}$ long. Photograph and radiograph are completely similar to those of sample SJ-17 (Fig.8; Bouma, 1964e, fig.4, 5). Box core SJ-59 from the Vigia Canyon (962 fathoms) is medium bedded. this being the only difference between SJ-52 (Fig.9).

\section{Canyon fan}

Only one sample was obtained from a canyon fan, being core LC VI-20, collected in a small gully in the La Jolla Canyon Fan at a depth of 562 fathoms. During pullingup manoeuvres and slicing operations the upper part of this sample was partly destroyed and is, therefore, not given in Fig.11 (see also BoumA, 1964e, fig. 14, 15).

The sedimentary structural picture of this core is completely similar to the 


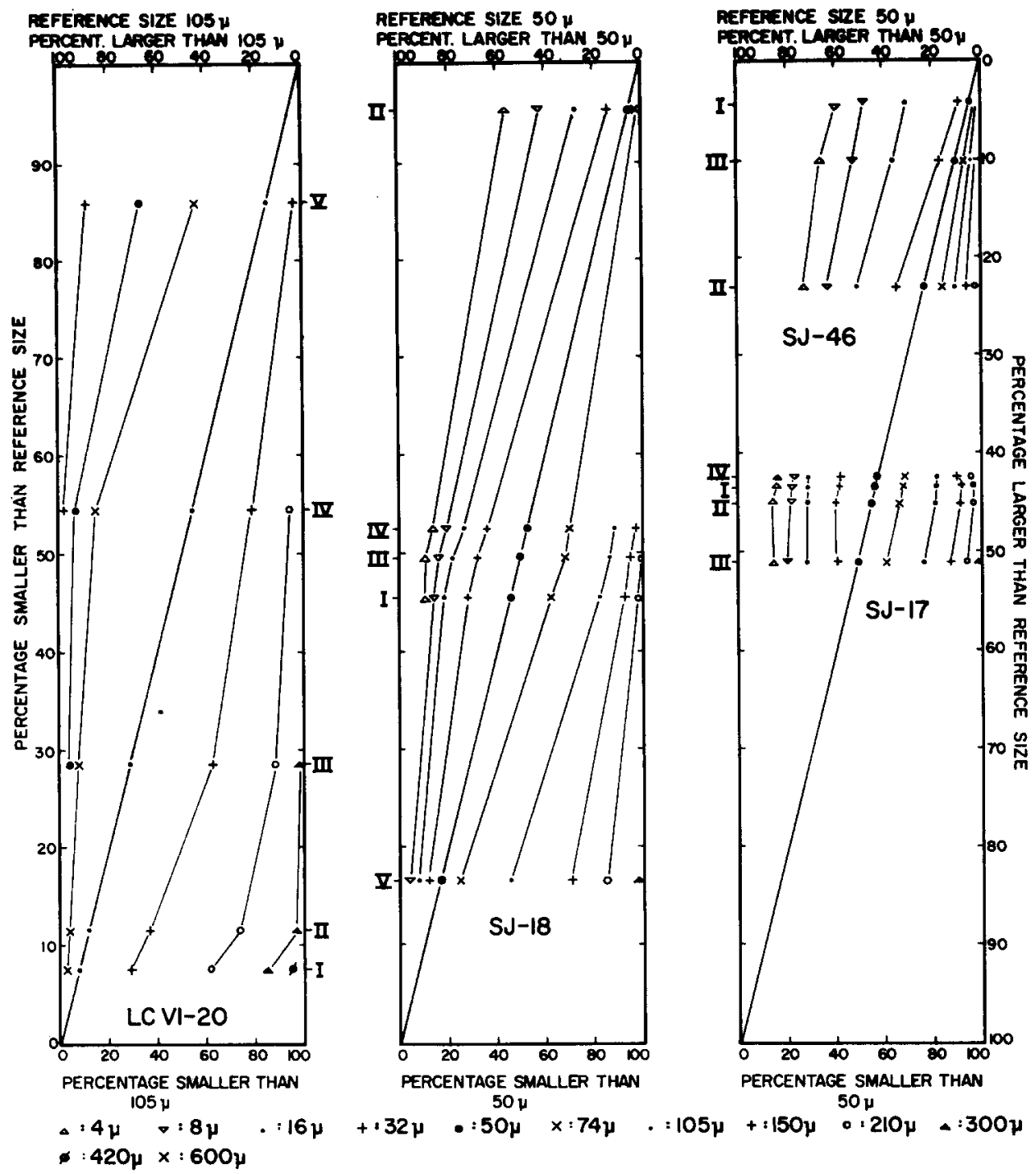

Fig.10. Rectangular diagrams presenting the grain-size distribution of samples collected from some radiographed slices. Sample points are indicated in Fig.8, 12, 13 and 17.

The grading within LC VI-20 is not regular since corresponding points do not lie on straight lines. Number IV contains too much of the fraction 32-50 $\mu$, and No. V too much 8-16 $\mu$.

There is no regular succession in the five samples of $\mathrm{SJ}-18$, but it can be observed that the connecting lines are smoothly curved which indicates that the samples all contain the same relative percentages of the corresponding fractions. Only the smallest fractions of sample II are a little too high, which is also true for the fractions $105-150$ and $150-210 \mu$ of sample $V$.

The fractions between $50-210 \mu$ of sample SJ-17 have practically constant percentages. This is the same for the fraction 8-16 $\mu$. The other fractions, smaller than the reference size, are not constant.

In the series II-III-I of sample SJ-46 one observes a sorting-out of the coarsest fractions. This is not the case with the finest fractions as the percentages of the fractions 8-16 and 16-32 $\mu$ of samples I and III are too high. 


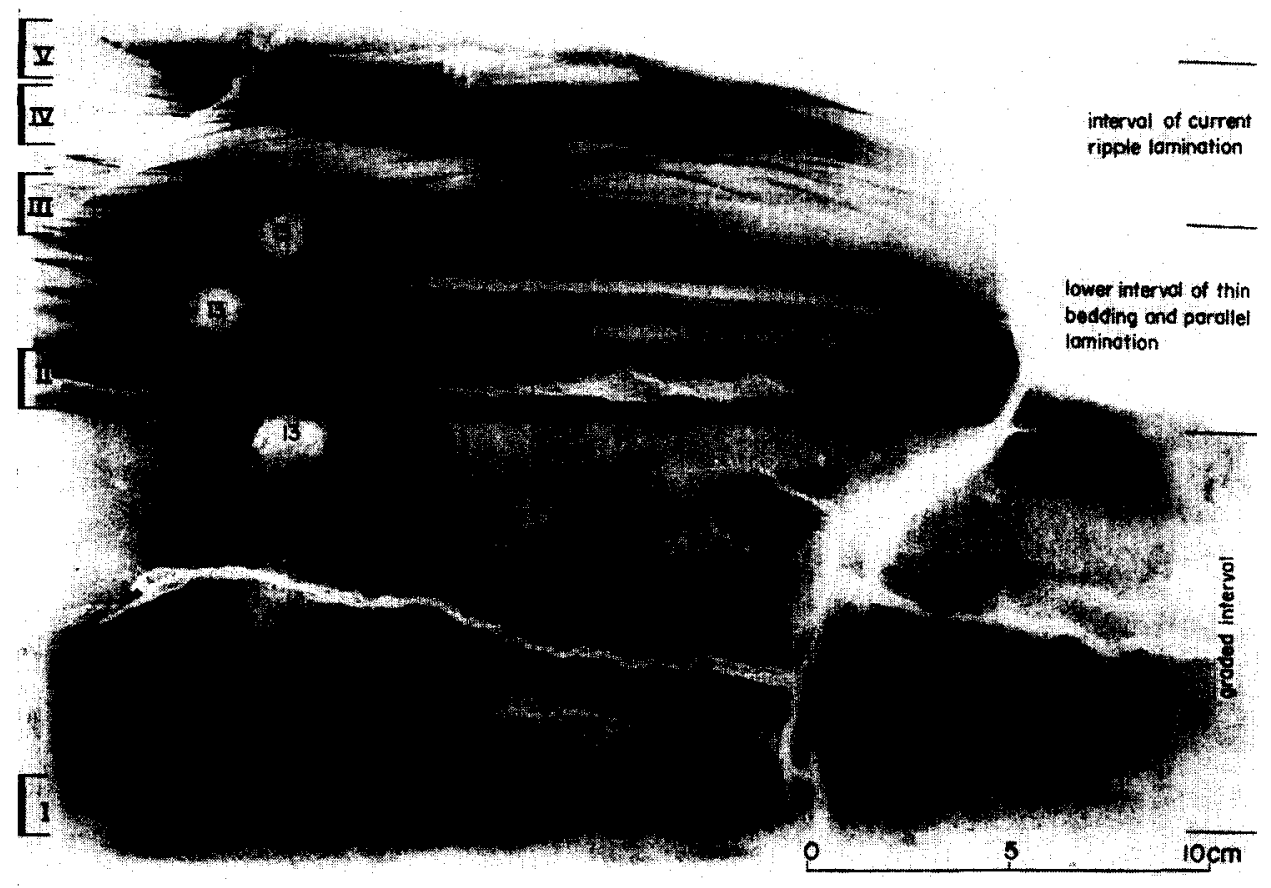

Fig.11. Print of a radiograph made of a vertical slice of sample LC VI-20, collected in a small gully in the La Jolla Canyon apron at a depth of 562 fathoms. This sample represents a Recent turbidite of which the lower three intervals of the turbidite facies model are present. The upper two intervals are missing by operational mistakes. The three white spots (13) are clay pebbles. The numbers along the side indicate places where samples have been taken for size analyses (see Fig.10). Slice thickness: 20 mm; Kodak Industrial film AA, $40 \mathrm{kV}, 5 \mathrm{~mA}, 150$ sec. (see also BoumA, 1964e, fig. 14, 15).

facies model of ancient turbidites (Bouma, 1962, 1964c, d) consisting of five intervals, each characterized by one sedimentary structure. These structures are, from bottom to top: graded or massif bedding, thin bedding or parallel lamination, current ripple lamination with or without convolute lamination, indistinct parallel lamination and pelitic interval without structures visible. A pelagic deposit may be present on top. The lacquer peel (Bouma, 1964e, fig. 14) made from a slice does not show the graded bedding, but only the thin bedding to parallel lamination with three clay pebbles, and rather distinct fore-set bedding (see also VAN STRAATEN, 1964). The radiograph (Fig.11) clearly reveals the contacts between the intervals and makes the sedimentary structures easy to distinguish. It demonstrates that the lower clay pebble (point 13) lies just in the graded interval. It can be observed that the clay pebbles are transported as pebbles, since surrounding laminae are bent or wedged out against the pebbles. The contact between the lamination and fore-set bedding is depositional and not erosional (cf. the remarks on sample LC VI-3 and BoUMA, 1964e, fig.17). The whole sample is well graded (Fig.10), but lamination and fore-set bedding predominate over the grading. 


\section{Sides of the axial part of the canyon}

All samples obtained in the central parts of the canyon, but outside the canyon axis, are much more clayey than the preceding ones. They still contain sand beds, but in total the sand layers are less than half of the sample. Slumping phenomena are more common. In the radiograph the clayey parts reveal more burrowing action, while the sandy parts mostly contain only parallel lamination.

A total of eight samples were recovered from the deeper canyon parts outside the actual axis. These come from the La Jolla Canyon: LC VI-15 at a depth of 276 fathoms; from the Coronado Canyon: LC V-12 at a depth of 670 fathoms (BoumA, 1964e, fig.10, 11), LC V-8 at a depth of 860 fathoms; from the Santa Maria Canyon SJ-18 at a depth of 183 fathoms (Fig.12; BoumA, 1964e, fig.18, 19), SJ-16 at a depth of 215 fathoms, SJ-23 at a depth of 733 fathoms (Fig.13, 14); from the San José Canyon at a depth of 1,377 fathoms; and from the Pescadero Canyon at a depth of 1,035 fathoms.

Sample LC VI-15 (depth 276 fathoms) from the La Jolla Canyon seems to be collected from the side of the axial canyon part, since it is a rather sandy core. The only structures visible are indistinct thin bedding with some lamination comparable to SJ-52 (Fig.9) and with some levels similar to the "convolute laminated" ones of LC VI-3 (BoumA, 1964e, fig.16, 17). The top part can be compared with the upper bed of LC IV-5 (Fig.3, 4).

Both samples from the Coronado Canyon are clayey. LC V-12 (Bouma, 1964e, fig. 10,11 ) is a slightly sandy clay, while LC V-8 (depth 860 fathoms) is a little sandier and contains one sand bed of $6 \mathrm{~cm}$ thickness with fore-set bedding at its base and indistinct parellel lamination on top of it. Both samples primarily show burrowing action at their radiographs. LC V-8 only reveals tube-shaped burrows; the other sample can be compared with SJ-22 (Fig.13, 14).

The samples SJ-16 (215 fathoms) and SJ-18 (183 fathoms) collected from the Santa Maria Canyon are partly similar. Both samples are bedded and show an increase in layer dip upward. SJ-16 is very thin-bedded to laminated. No distinct structures are visible, probably due to slight slump movements. SJ-18 (Fig.12; BoumA, 1964e, fig.18, 19) also presents some irregular indistinct beds, but besides this a distinct clay layer (point 14), with erosion on top and a clear filling-up of the erosion depressions, can be observed. The offset (point 15) is no fault, as one may think upon examining the photograph (BoumA, 1964e, fig.18), but is also an erosional feature. The fault (point 16) at the top is not artificial. In sample SJ-16 two similar funnelshaped burrows are visible, as can be seen in Fig. 12 at point 17 . The result of five grainsize analyses are given in Fig.10.

Sample SJ-22 (732 fathoms) is completely reworked. The photograph (Fig.13) does not show any structures, only some concentrations of sand grains. The radiograph (Fig.14), however, detects the presence of a large number of all types of burrows, as have also been found in samples LC V-12, LC VI-16 and SJ-45 (BoumA 1964e, fig. 11, 21, 7 respectively). The large ones (point 18) may have been made 


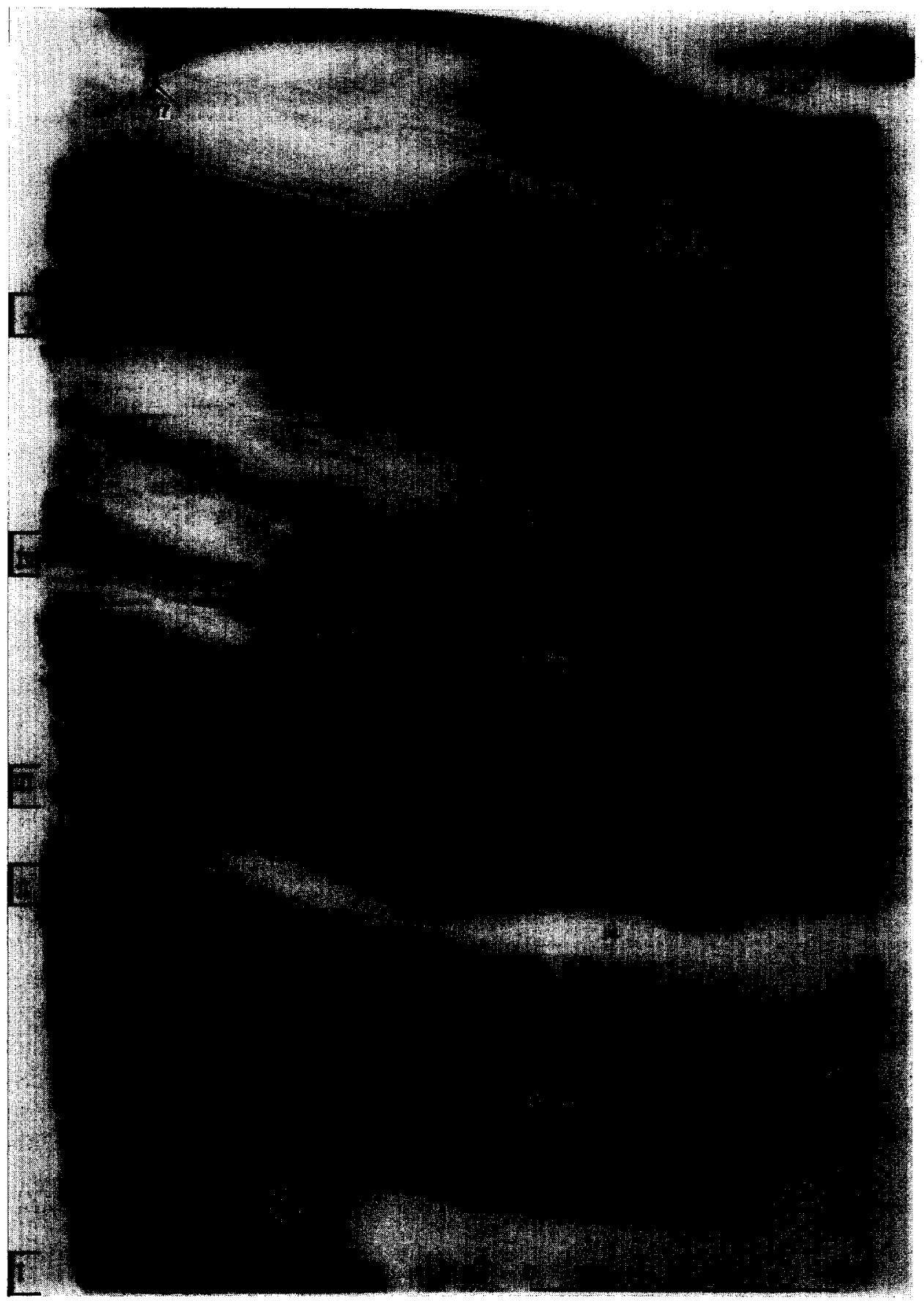

Fig.12. Print of a radiograph made of a vertical slice of sample SJ-18, collected near the axial part of the Santa Maria Canyon at a depth of 183 fathoms. The dark parts are sandy, the grey coloured parts clayey sand, whilst the light coloured part underneath the erosional contact is a clay (14). In the upper right-hand corner a fault is visible (16). The numbers along the side indicate places where samples have been taken for size analyses (see Fig.10). Slice thickness: $12 \mathrm{~mm}$; Kodak Industrial film AA, $40 \mathrm{kV}, 5 \mathrm{~mA}, 2 \mathrm{~min}$. (see also Bouma, 1964e, fig.18, 19). 


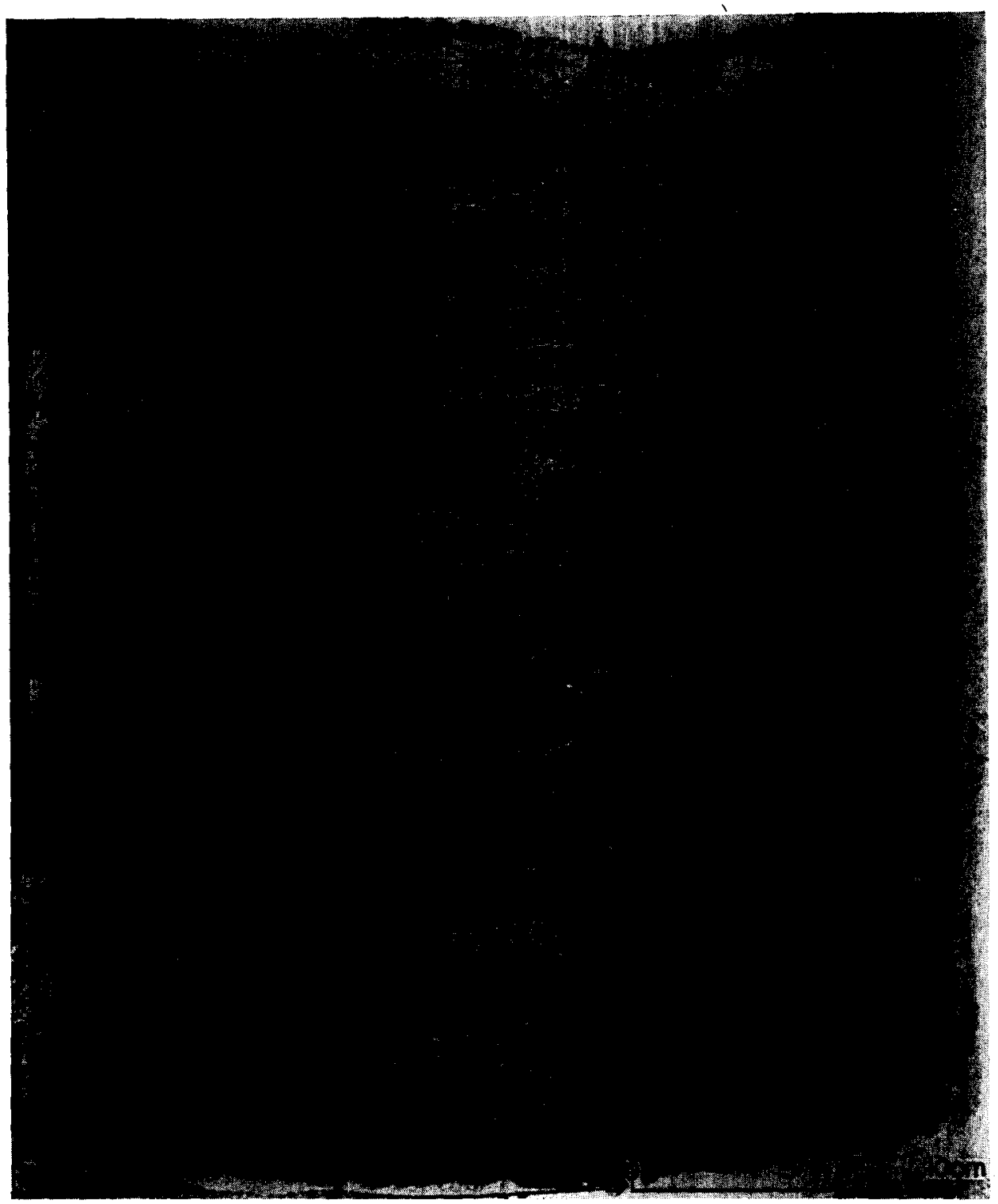

Fig.13. Photograph of a vertical slice of sample SJ-22, collected near the axial part of the Santa Maria Canyon at a depth of 733 fathoms. No sedimentary structures are visible.

by an Echinocardium sp. (cf. REINECK, 1963b), while the oval sections (point 19) can be explained as cross sections through this type of burrow. Reineck only found them in sand. Another type are the small burrows which can be found as nests or as chain-like configurations (point 20; compare with LC V-12 in BouMA, 1964e, fig.11). The rest of the sample is somewhat mottled and part of the mottlings can be interpreted as burrows. Some slump action of the upper $7 \mathrm{~cm}$ seems likely. Sample SJ-27 


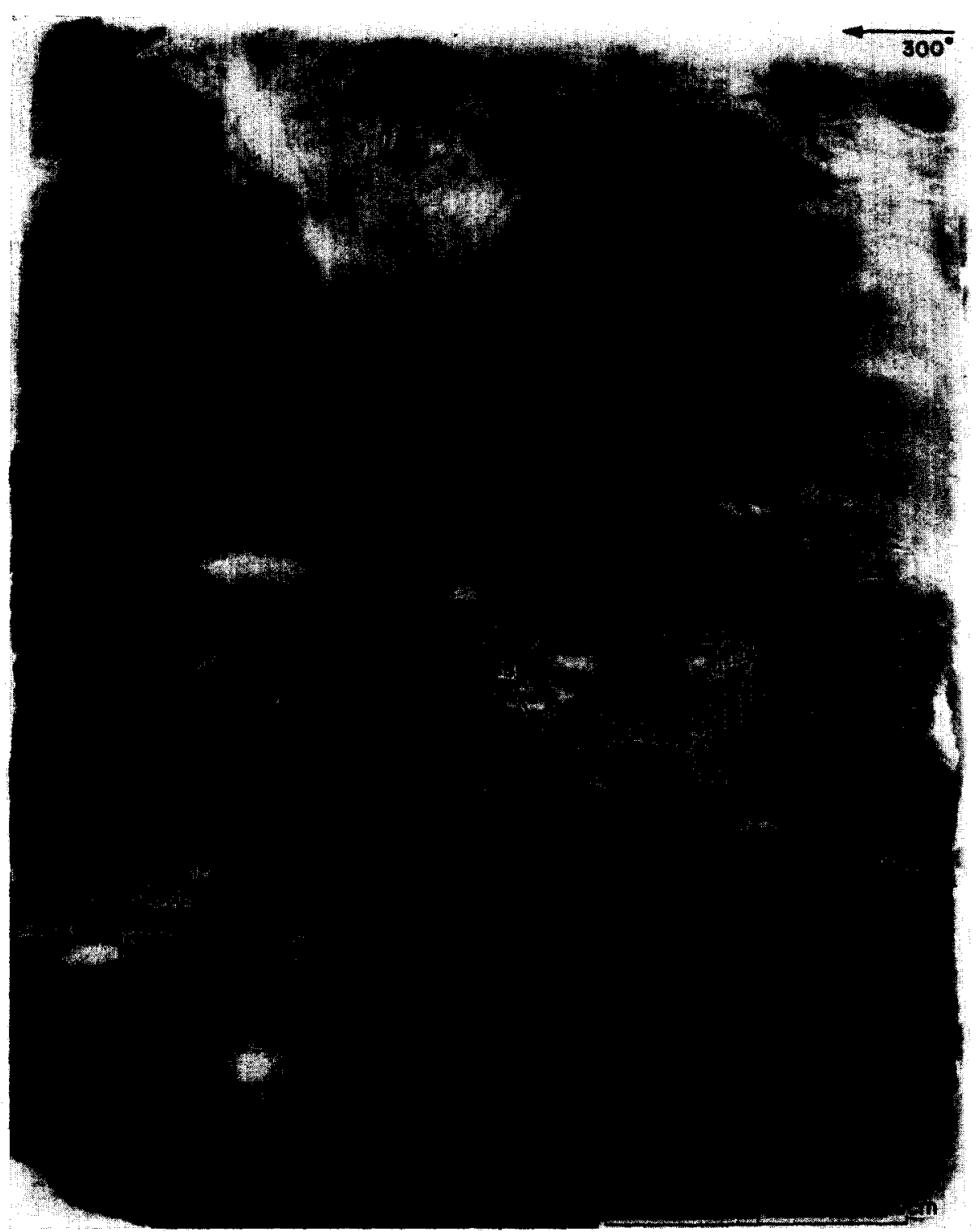

Fig.14. Print of a radiograph made of the slice given in Fig.13. The whole sample is completely reworked by several types of burrows $(18,19,20)$. Slice thickness: $12 \mathrm{~mm}$; Kodak Industrial film AA, $40 \mathrm{kV}, 5 \mathrm{~mA}, 2 \mathrm{~min}$.

from a depth of 1,377 fathoms of the San José Canyon can be compared with SJ-22. It is completely reworked by burrows, but slump action masked their clearness. Part of the points may be pellets.

Sample SJ-46 was collected in the Pescadero Canyon at a depth of 1,035 fathoms. It is a slightly sandy micaceous grey-green clay with two irregular sand beds in it (Fig.15, 16; Bouma and Marshall, 1964, fig.9). The upper third part is influenced 


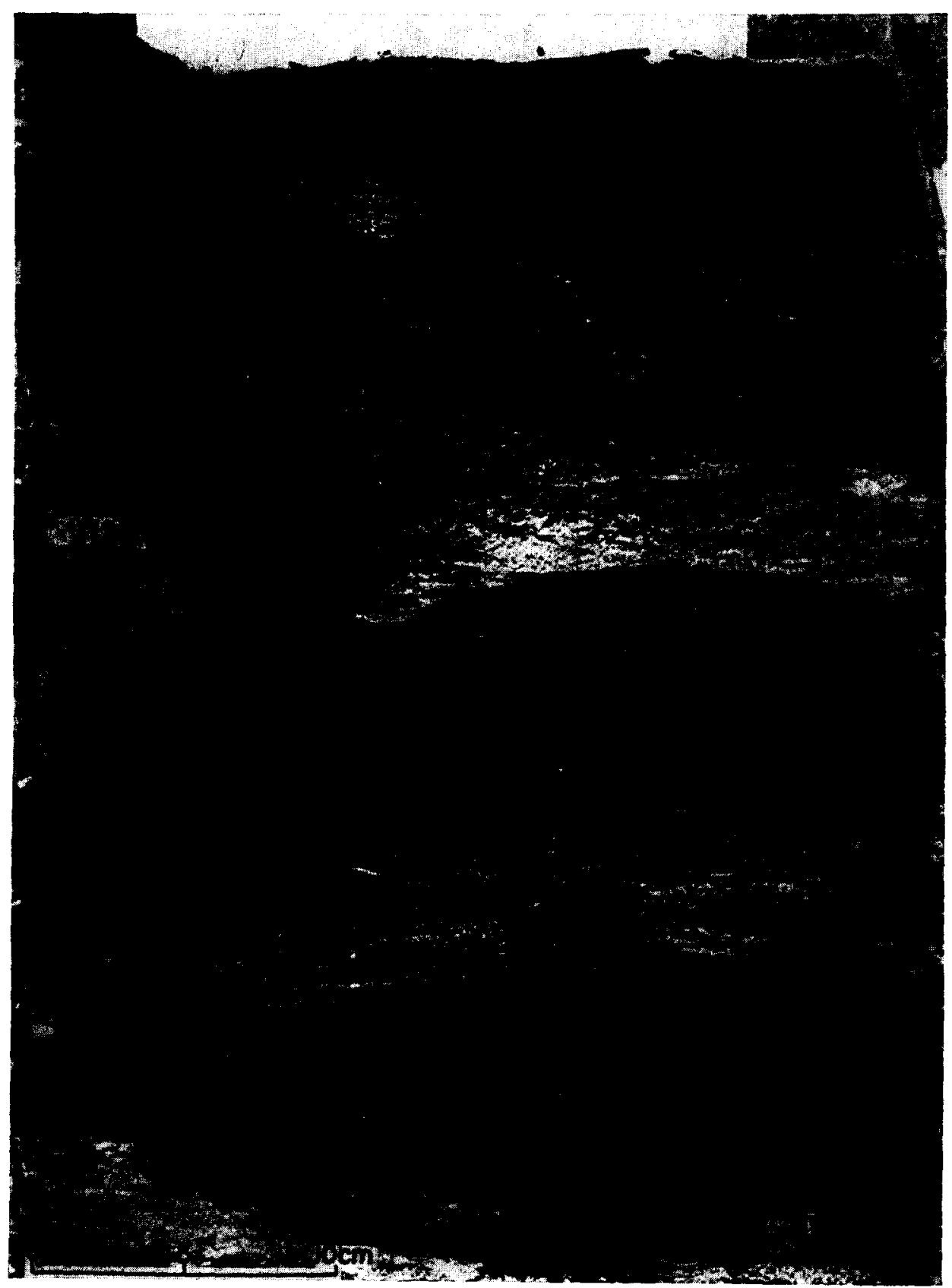

Fig.15. Photograph of a vertical slice of sample SJ-46, collected near the axial part of the Pescadero Canyon at a depth of 1,035 fathoms. The green-greyish micaceous sandy clay contains two irregular sand beds. No sedimentary structures are visible. 


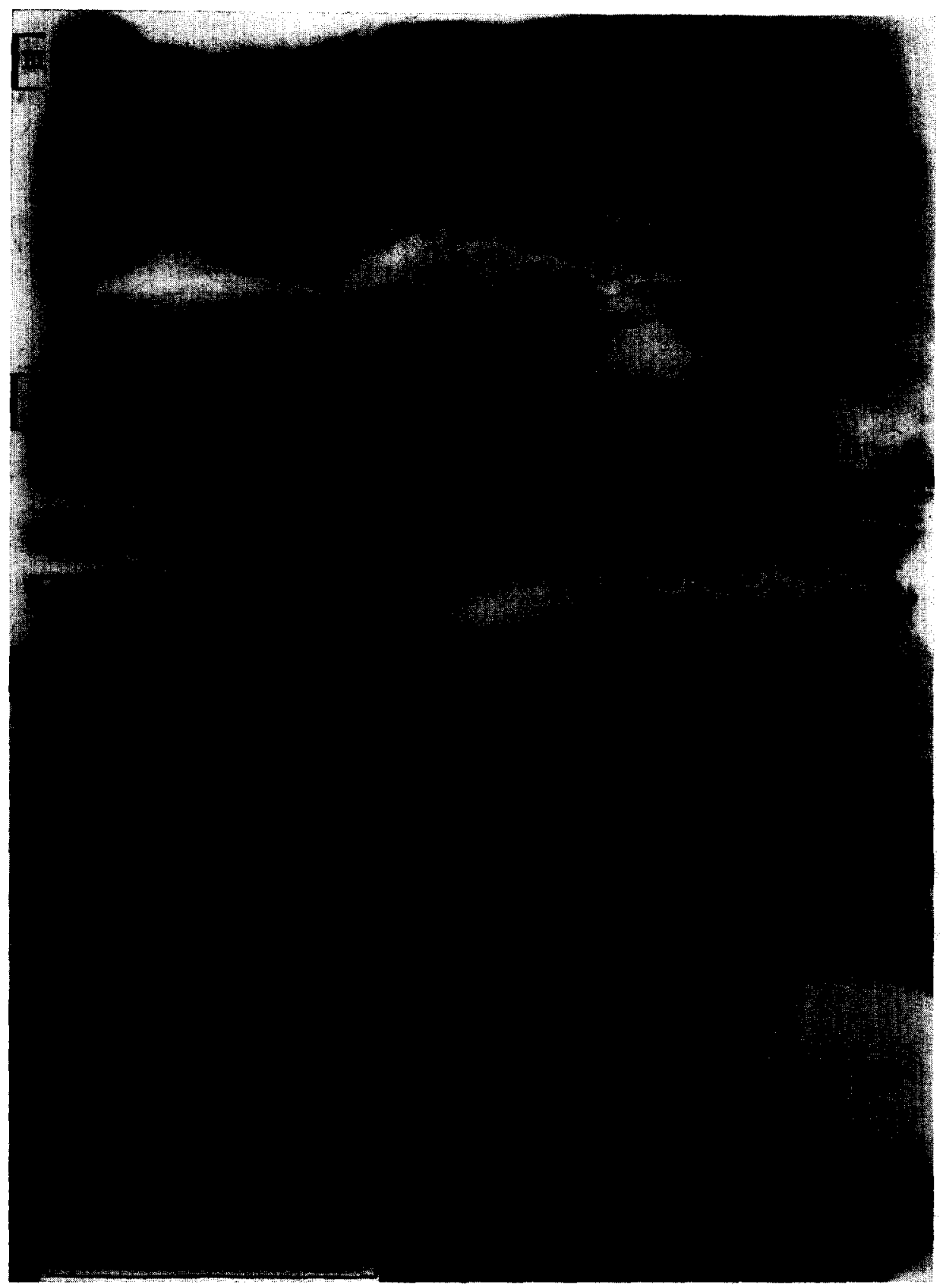

Fig.16. Print of a radiograph made of the slice given in Fig.15. The two sand beds contain irregular lamination (14), the upper one also contains two internal load casts or slump balls (21). Some burrows are visible (25). The numbers along the side indicate places of samples for size analyses (see Fig.10). Slice thickness: $12 \mathrm{~mm}$; Kodak Industrial film AA, $40 \mathrm{kV}, 5 \mathrm{~mA}, 135 \mathrm{sec}$. 
by slumping and no other sedimentary structures are visible. This part is underlain by an irregular sand bed in which two slump balls (point 21), indistinct lamination and a lenticular form (point 22), and a clay pebble can be observed. Around the slump balls the lower bedding plane is irregular, due to load casting in the underlying clay. Underneath the lamination the clay contains some small-sized burrows. The lower half of this sample can be divided into four zones. These are from bottom to top: a sandy-clayey part without determinable features, a sand bed with irregular parallel thin bedding and lamination (point 24), a sandy clay with burrows (point 25), and a thin sand bed on top (point 26). A slight destruction by slumping masks the clearness of the properties present. The results of three grain size analyses are given in Fig. 10 .

\section{Canyon terrace}

Parts of the La Jolla Channel reveal the presence of a terrace before one reaches the canyon axis by running profiles over this incision (see also BufFINGTON, 1964). One sample, LC VI-16, was collected from the terrace at 310 fathoms (for figures see BoumA, 1964e, fig.20, 21). The photograph presents a dark green coloured clay with little mica and silt, and with some sand grains. No sedimentary structures can be observed. The radiograph reveals a completely mottled structure in which a number of images can be detected as burrows. There is an irregular distribution of dark coloured spots, being sand patches, while the rest of the sample is clayey (comparable with the top part of Fig.17).

\section{Canyon edges or shelf}

Two samples were obtained from the shelf near the canyon. One (LC VI-1) came from a depth of 316 fathoms from the northern side of the canyon (for photograph and radiograph see BoumA, 1964e, fig.8, 9), the other one (LC VI-5) from the south rim at a depth of 313 fathoms (Fig.17). The locations are given in Fig.1.

The photographs of both samples are completely similar. The material is a dark gray coloured clayey sediment without any structures visible. The radiographs show, next to the slightly mottled clayey mass, the presence of a number of darker coloured surfaces. Fig. 17 presents the radiograph made from LC VI-5. The darker coloured surfaces (point 27) are silt lumps. Some burrowing activity through them can be observed (point 28 ). It seems likely that originally there were at least two silt bands, but that they were partly destroyed and removed by burrowing and slumping. Part of the mottling may be due to pellets.

\section{Offshore basin}

A photograph and a radiograph of a core collected offshore are given by BoumA (1964e, fig.6, 7). During topography recording we found north of a seamount a 


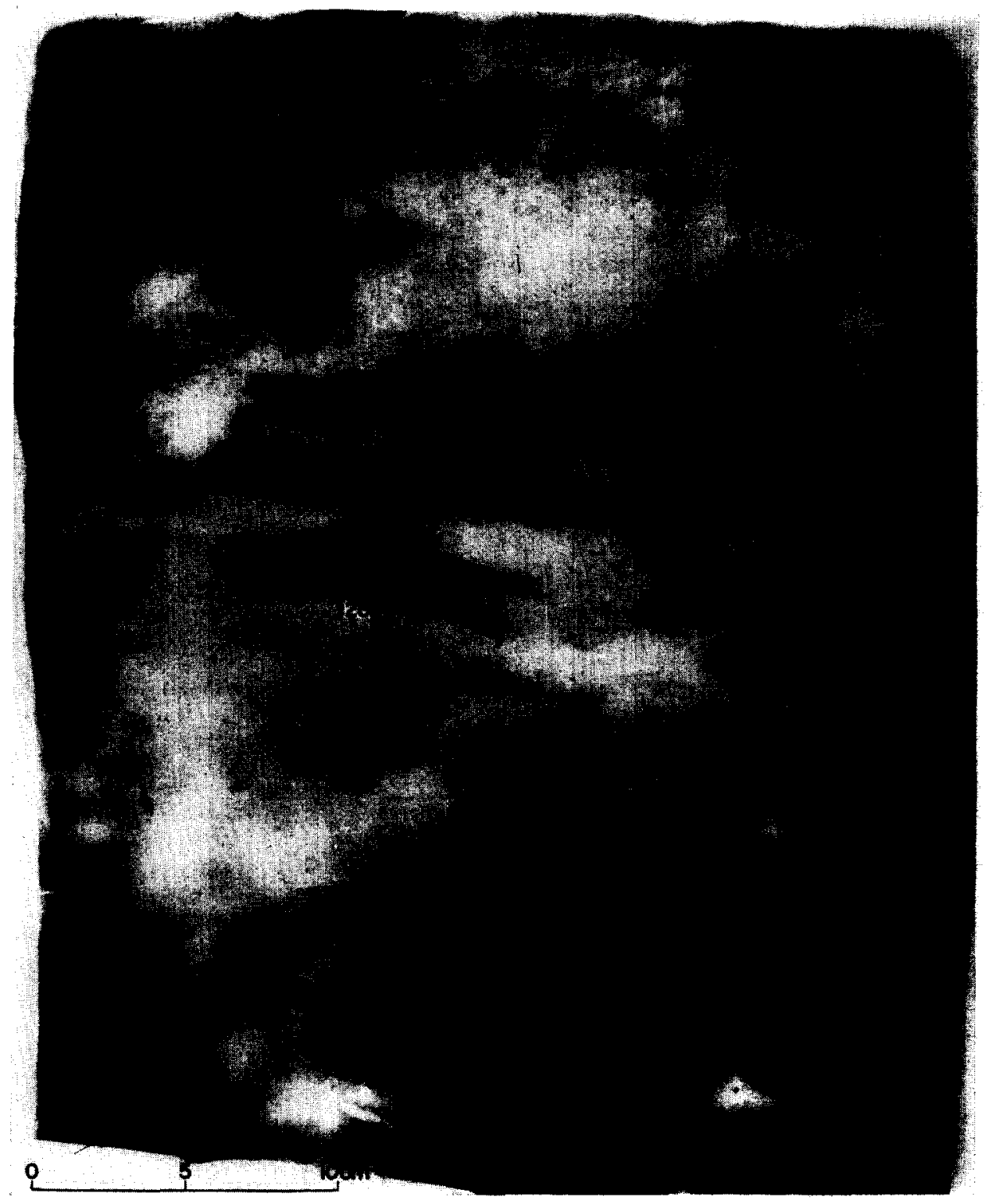

Fig.17. Print of a radiograph of a vertical slice from sample LC VI-5, collected at the south of the La Jolla Channel at a depth of 313 fathoms. The dark coloured surfaces in the middle are silt lumps (27). Slice thickness: $12 \mathrm{~mm}$; Kodak Industrial film AA, $40 \mathrm{kV}, 5 \mathrm{~mA}, 90 \mathrm{sec}$.

small flat-floored basin with a small gully with levees. From this gully a gravity core was collected, consisting of sand with some pelite intercalations. Apart from lamination, no structures were observed and no radiographs were made. The box core, collected a little outside the northern levee, presents a clayey sediment with one sand 
bed in its lower part. The normal picture does not present any structures; the radiograph reveals slumping, several types of burrows, and inclusions in the sand bed (wood rests).

\section{CONCLUSIONS}

Not enough cores have yet been collected to be able to draw decisive conclusions. Also the number of submarine canyons investigated is too small. It seems necessary to make combined samplings with piston, gravity and box corers at rather short distances along the axis of well-surveyed canyons and regularly dense sampling lines at right angles to the axis. Accurate positioning is essential.

Careful and detailed surveys must be made to investigate the topographical features such as the course of the axis, position of terraces and small offsets (BUFFINGTON, 1964).

Besides normal pictures and radiographs, peels with normal or high relief and impregnation techniques should be applied (BouMA, 1964b, in preparation) for further analyses, while the rest of the box samples can be used for other types of investigations such as grain size, mineralogy, carbonate, fossil content, percentage of organic material, radiocarbon dating, etc. As soon as a box sample is aboard, it would appear useful to make shear-strength measurements straight away, as was done by $R$. F. Dill on some of the described samples (DiLL, 1964b; Dill and Moore, 1965). This can later be followed by analyses on the liquid limit, plastic limit, plasticity index, specific gravity, void ratio, natural moisture content, and unit-weight analyses as was done by MORGAN et al. (1963).

In spite of differences concerning the formation of the canyons and the petrological compositions of the rocks in which a submarine canyon erodes its valley, these submarine incisions have many corresponding features (SHEPARD, 1963a, b, 1964; DiLl, 1964a, b).

The box cores collected from the axial part are sandy and sometimes contain gravel, whilst the content of finer sizes is rather small. Mica and plant fiagments may be abundant and clay pebbles common. Indistinct graded bedding, parallel lamination and current-ripple lamination are the primary sedimentary structures observed; burrowing and slumping are not common. In general it can be said that secondary structures are scarce in this group.

The sample from the apron is comparable with ancient turbidites. Sediments from the canyon axis may contain structures known from turbidites but they are not even similar to part of the turbidite facies model. Core LC VI-3 presents parallel lamination with current ripple lamination on top, as is the same with the intervals $b$ and $c$ of the facies model. In a turbidite the contact between these intervals is transitional, as far as is known to the author, and not erosional as can be observed in sample LC VI-3 (compare fig. 15 and 17 in BoumA, 1964e). Turbidity currents must be initiated higher up in the canyon if turbidites are to be found on the apron (see also GoRSLINE 
and Emery, 1959; Stanley and Bouma, 1964, fig.17). From the observations made by DILL (1964b) it may be said that this does not occur in the canyon heads where slopes are the steepest. Even earthquakes do not seem to have a considerable influence on the mass movements in the heads (DILl, 1964b).

The samples collected outside the axial part contain a high amount of burrows in the clayey parts. Most of the cores are bedded. From this the idea can be obtained that occasionally sand also moves outside the axial part. It cannot be concluded whether this material is transported by a slump, a turbidity current or another transport agent.

It seems likely that the transport was not purely a mass movement, since too little erosion has been observed and the layers are rather thin. The presence of lamination and fore-sets in the sands also indicates transport by traction.

The sample in the middle of the Gulf of California indicates that at least one sand movement has passed the gully whilst part of the sand flowed over the levees. The rest of the sample can be compared with the one from the canyon terrace and the shelf cores. This clay sedimentation is slow and the conditions are favourable for intensive burrowing action. The occasional sand grains can be brought in by wind and by drifting plant fragments.

The slumps, which normally occur in the finer grained samples, indicate instability of the sedimentation areas. Topographical differences are normal at places where these cores have bzen collected. The small grain size, the presence of mica and the abundance of burrows may be sufficient for slump action. Mass movements may also occur. Examining sample SJ-17 (Fig.8) one gets the impression that the two sediment units are not deposited upon each other. Whether there has been erosion of the gravelly part or movement of the upper part by mass movement, cannot be concluded.

The examples given clearly indicate the need of further detailed research before definite answers can be given on the transport agents in submarine canyons.

\section{ACKNOWLEDGEMENTS}

The author is greatly indebted to Dr. F. P. Shepard, who made it possible to obtain a Sverdrupp post-doctoral fellowship to study for a year at the Scripps Institution of Oceanography, La Jolla, California, and who enabled him to collect the box samples. He wants to thank Dr. R. F. Dill for all his help and specially for the many interesting diving hours spent in observing canyon heads. He is grateful to Mrs. Shepard, to the captain and crew of the R. V. "Spencer F. Baird", and to all colleagues for their assistance during these trips. N. F. Marshall also helped with slicing and radiographying the samples, $R$. van Dijk and B. Dekker made the drawings, J. H. Elsendoorn the analyses and the final prints. I give them all my thanks and gratitude. The final manuscript was critically read by Drs. J. R. Curray, D. J. Doeglas and F. P. Shepard. I thank them for their corrections and improvements. 


\section{REFERENCES}

Bouma, A. H., 1962. Sedimentology of some Flysch Deposits, a Graphic Approach to Facies Interpretation. Elsevier, Amsterdam, 168 pp.

Bouma, A. H., 1963. Facies model of salt marsh deposits. Sedimentology, 2 : 122-129.

Bouma, A. H., 1964a. Self-locking compass. Marine Geol., 1 : 181-186.

Bouma, A. H., 1964b. Sampling and treatment of unconsolidated sediments for study of internal structures. J. Sediment. Petrol., $34: 349-354$.

Bouma, A. H., 1964c. Turbidites. In: A. H. Bouma and A. Brouwer (Editors), Turbidites. Elsevier, Amsterdam, pp. 247-256.

BoumA, A. H., 1964d. Ancient and Recent turbidites. Geol. Mijnbouw, 43 : 375-379.

BoumA, A. H., 1964e. Notes on X-ray interpretation of marine sediments. Marine Geol., 2 (4) :278-309.

Bouma, A. H., in preparation. Methods in the study of sedimentary structures.

Bouma, A. H, and Marshall, N. F., 1964. A method for obtaining and analysing undisturbed oceanic sediment samples. Marine Geol., 2 (1/2) : 81-99.

Bouma, A. H. and SHEPARD, F. P., 1964. Large rectangular cores from submarine canyons and fan valleys. Bull. Am. Assoc. Petrol. Geologists, 48 (2) : 225-231.

Buffington, E. C., 1951. Gullied submarine slopes off southern California (abstract). Bull. Geol. Soc. Am., $62: 1497$.

Buffington, E. C., 1964. Structural control and precision bathymetry of La Jolla submarine canyon, California. Marine Geol., 1 : 44-58.

Calvert, S. E. and Veevers, J. J., 1962. Minor structures of unconsolidated marine sediments revealed by X-radiography. Sedimentology, $1: 296-301$.

DilL, R. F., 1964a. Features in the heads of submarine canyons, narrative of an underwater film. In: L. M. J. U. VAn StraAten (Editor), Deltaic and Shallow Marine Deposits. Elsevier, Amsterdam, pp. 101-104.

DilL, R. F., 1964b. Contemporary Submarine Erosion in Scripps Submarine Canyon. Thesis, Univ. California, Scripps Inst. Oceanograph., La Jolla, 269 pp.

Dill, R. F. and Moore, D. G., 1965. A diver-held vane shear apparatus. Marine Geol., in preparation.

DoEglas, D. J., 1955. A rectangular diagram for comparison of size-frequency distributions. Geol. Mijnbouw, $17: 129-136$.

Doeglas, D. J., 1960. Sedimentological data for soil mineralogy. Proc. Intern. Conf. Soil Sci., 7th, Madison, U.S.A., 7 (13) : 534-547.

DoEglas, D. J., 1962. A graphic approach to the interpretation of variations in the size-frequency distribution of silty clays. Bull. Franc. Argiles, 13 (8) : 3-14.

EMERY, K. O., 1960. The Sea off Southern California. Wiley, New York, N.Y., 366 pp.

EMERY, K. O. and HülsEMANN, J., 1963. Submarine canyons off southern California. 1. Topography, water, and sediments. In: Allan Hancock Pacific Expeditions, Univ. Southern Calif. Press, Los Angeles, 27 (1) : 80 pp.

Gorsline, D. S. and Emery, K. O., 1959. Turbidity-current deposits in San Pedro and Santa Monica Basins off southern California. Bull. Geol. Soc. Am., 70 : 279-290.

Hamblin, W. K., 1962. X-ray radiography in the study of structures in homogeneous sediments. J. Sediment. Petrol., $32: 201-210$.

Morgan, J. P., Coleman, J. M. and Gagliano, S. M., 1963. Mudlumps at the mouth of South Pass, Mississippi River; sedimentology, paleontology, structure, origin, and relation to deltaic processes. Louisiana State Univ. Studies, Coastal Studies Ser., $10: 190$ pp.

ReINECK, H. E., 1958. Kastengreifer und Lotröhre "Schnepfe". Senckenbergiana Lethaea, 39 (1-2) : $45-48$.

REINECK, H. E., 1963a. Der Kastengreifer. Natur Museum, 93 (2) : 65-68.

REINECK, H. E,, 1963b. Sedimentgefüge im Bereich der südlichen Nordsee. Abhandl. Senckenberg. Naturforsch. Ges., $505:$ 1-138.

ShePard, F. P., 1951. Mass movements in submarine canyon heads. Trans. Am. Geophys. Union, $32: 405-418$.

ShePARd, F. P., 1961. Deep sea sands. Intern. Geol. Congr., 21st, Copenhagen, 1960, Rept. Session, Norden, $23: 26-42$.

ShePARD, F. P., 1963a. Submarine Geology, 2 ed. Harper, New York, N.Y., 557 pp. 
Shepard, F. P., 1963b. Submarine canyons. In: M. N. Hill, E.D. Goldberg, C. O'D. Iselin and W. H. MUNK (Editors). The Sea, Ideas and Observations on Progress in the Study of the Seas, 3. The Earth beneath the Sea. Interscience, New York, N.Y. pp. 480-506.

ShePard, F. P., 1964. Sea floor valleys of the Gulf of California. In: Marine Geology of the Gulf of California-Am. Assoc. Petrol. Geologists, Mem., 3:157-192.

SHEPARD, F. P. and EINSELE, G., 1962. Sedimentation in San Diego Trough and contributing submarine canyons. Sedimentology, $1: 81-133$.

SHePARd, F. P. and EMERY, K. O., 1941. Submarine topography off the California coast: canyons and tectonic interpretation. Geol. Soc. Am., Spec. Papers, $31: 171 \mathrm{pp}$.

StANLEY, D. J. and Bouma, A. H., 1964. Methodology and paleogeographic interpretation of Flysch formations: a summary of studies in the maritime Alps. In: A. H. BOUMA and A. BrouWER (Editors), Turbidites. Elsevier, Amsterdam, pp.34-64.

Van StraAten, L. M. J. U., 1964. Turbidite sediments in the southeastern Adriatic Sea. In: A. H. BOuma and A. Brouwer (Editors), Turbidites. Elsevier, Amsterdam, pp.142-147. 